International Journal of Biology, Pharmacy and Allied Seiences (IJBPAS) 'A Bridge Betusen caboratorymd QReado'

Www.ibpas.com

\title{
ASSESSMENT OF COVID-19 FEAR AMONG THE UNDERGRADUATES - A CROSS-SECTIONAL STUDY
}

\author{
AMIT UPASANI ${ }^{*}$, MANISHA DUNGHAV ${ }^{2}$ \\ 1: Associate Professor and PhD Sch., Dept. of Samhita Siddhanta; Parul Institute of \\ Ayurved, Parul University, Vadodara, Gujarat \\ 2: 2.HOD and Professor, Dept. of Samhita Siddhanta, Parul Institute of Ayurved \& \\ Research, Parul University, Vadodara, Gujarat
}

*Corresponding Author: Dr. Amit Upasani; E Mail: amit.upasani@paruluniversity.ac.in

Received $3^{\text {rd }}$ Jan 2022; Revised $11^{\text {th }}$ Jan 2022; Accepted $20^{\text {th }}$ Jan. 2022; Available online $25^{\text {th }}$ Jan. 2022 https://doi.org/10.31032/ijbpas/2022/11.1.2050

\begin{abstract}
Background: Coronavirus disease is a highly infectious and fatal disease. It has caused distress in the form of fear, and anxiety among masses including youth. To observe the Covid -19 Fear in the youth undergraduate students studying in bachelor studies in Ayurveda were selected for the study. Materials and Methods: Participants- Total 183 volunteers participated in the study. Participants were undergraduate students of Parul Institute of Ayurveda. The present study was cross-sectional study conducted in the month of December 2021. A valid questionnaire's Google form is circulated through the whats app group to the participants. Though enormous vaccination was given the fear still exists. Conclusion: There is definite impact of vaccination on the Covid-19 fear, but still in some cases fear plays a major role in aggravation of the disease
\end{abstract}

Keywords: COVID-19, Fear, Undergraduate students

\section{INTRODUCTION:-}

Corona virus disease is a contagious disease 2019(COVID-19) caused by severe acute respiratory syndrome Coronavirus 2 . The first case was identified in Wuhan,
China in Dec. 2019. After that it spreads worldwide and also in India first case was reported in kerala on $30^{\text {th }}$ of January. According to official figures, India has the 
second-highest number of confirmed cases in the world (after the United States of America)

Lockdowns were announced in Kerala on 23 March, and in the rest of the country on 25 March. On 10 June, India's recoveries exceeded active cases for the first time. Infection rates started to drop in September, along with the number of new and active cases. Daily cases peaked midSeptember with over 90,000 cases reported per-day, dropping to below 15,000 in January 2021. A second wave beginning in March 2021 was much more devastating than the first, with shortages of vaccines, hospital beds, oxygen cylinders and other medical supplies in parts of the country. By late April, India led the world in new and active cases. On 30 April 2021, it became the first country to report over 400,000 new cases in a 24-hour period. There after it's slowly decrease in the cases but not totally disappeared.

Fear is a natural, powerful, and primitive human emotions. Human emotions are different according to various opinions as six, eight, ten, twenty seven etc. In everywhere fear is mentioned as one of the emotions. It involves a universal

\section{Participants:-}

Total 183 volunteers participated in the study. Participants were undergraduate

\section{Study Design:-}

biochemical response as well as a high individual emotional response. Fear alerts us to the presence of danger or the threat of harm, whether that danger is physical or psychological. Sometimes fear stems from real threats, but it can also originate from imagined dangers. Fear can also be a symptom of some mental health conditions including panic disorder, social anxiety disorder, phobias, and post-traumatic stress disorder

In February 2021 India has started world's largest vaccination drive for the COVID19. In the month of Dec. 2021 around 143.3 $\mathrm{Cr}$. vaccine dosagein that 85 percentage of total eligible population in the country received at least first dose of vaccine and 64 percentage having both doses of vaccine. Though this is reality after the vigorous vaccination also due to new variant i.e. B. 1.1.529 (SARS - CoV-2) also known as Omicron there is a fear in the mind of people. Primary information shows it's not much severe but transmission rate is higher. In view of current situation this study is an attempt to analyse the fear related to COVID-19 in the students of medical fraternity.

MATERIALS AND METHODS:students of Parul Institute of Ayurveda Parul University. The age of participants from 18 to 22 years. 
The present study was cross-sectional study conducted in the month of December 2021.

Data Collection tool and technique:

Google form of valid questionnaire of fear related to COVID-19 developed by Ahorsu et al. ${ }^{1}$ was generated to collect the data. This questionnaire is a reliable tool for the assessment of fear of COVID-19. A snowball sampling technique was used to identify teachers and link of the questionnaire was sent to student's what Sapp so that they could share with other students. The link for the study was initiated on $14^{\text {th }}$ of December 2021 and was active for 10 days i.e. till $24^{\text {th }}$ of December 2021. The study included only respondents who understood English and had access to the Internet.

I am most afraid of coronavirus-19.

183 responses

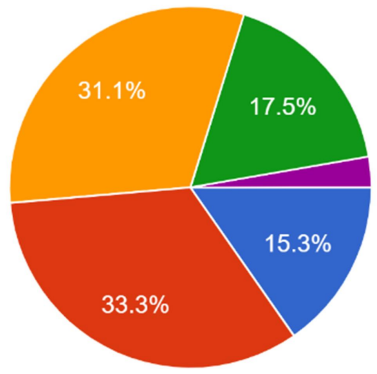

II) It makes me uncomfortable to think about coronavirus-19:- All participants attended this question and mostly i.e. 73

\section{OBSERVATION AND RESULTS:-}

1. Age: - All the participants were in between the age group of 18 to 23 years. Maximum of 80 participants were of the age 21 years and one participant was below 23 years of age. Number of participants between 18-20 years of age were 55 .

2. Gender:- In the study total 100 participants were female and 83 were Male.

3. Course:- All participants were enrolled in the under graduation course i.e. in Bachelor of Ayurveda Medicine and Surgery.

4. Questions of the questionnaire:-

I) I am most afraid of coronavirus-19. :This question was attempted by all the participants out of these 61 participants answered Disagree to this question.

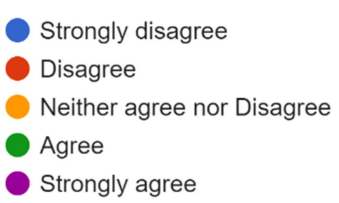

participants answered Disagree to this question. 
It makes me uncomfortable to think about coronavirus-19

183 responses

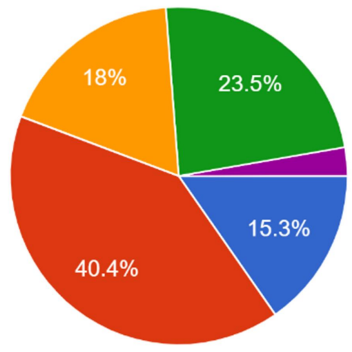

Strongly disagree

Disagree

Neither agree nor Disagree

Agree

Strongly agree

III) My hands become clammy when I mostly i.e. 90 participants answered think about coronavirus-19:- All Disagree to this question.

participants attended this question and

My hands become clammy when I think about coronavirus-19.

183 responses

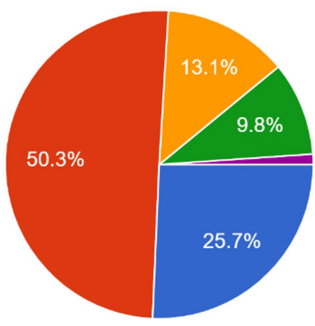

Strongly disagree

Disagree

Neither agree nor Disagree

Agree

Strongly agree

IV) I am afraid of losing my life because of

this question and mostly i.e. 58 participants coronavirus-19:- All participants attended answered Disagree to this question.
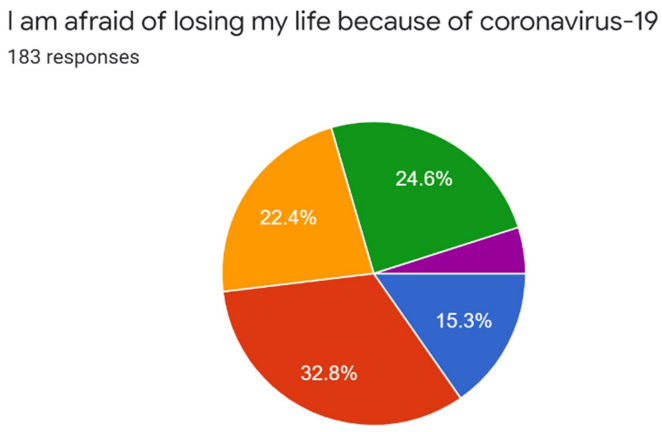

Strongly disagree

Disagree

Neither agree nor Disagree

Agree

Strongly agree

V) When watching news and stories about coronavirus-19 on social media, I become nervous or anxious: - All participants attended this question and mostly i.e. 68 participants answered Disagree to this question. 

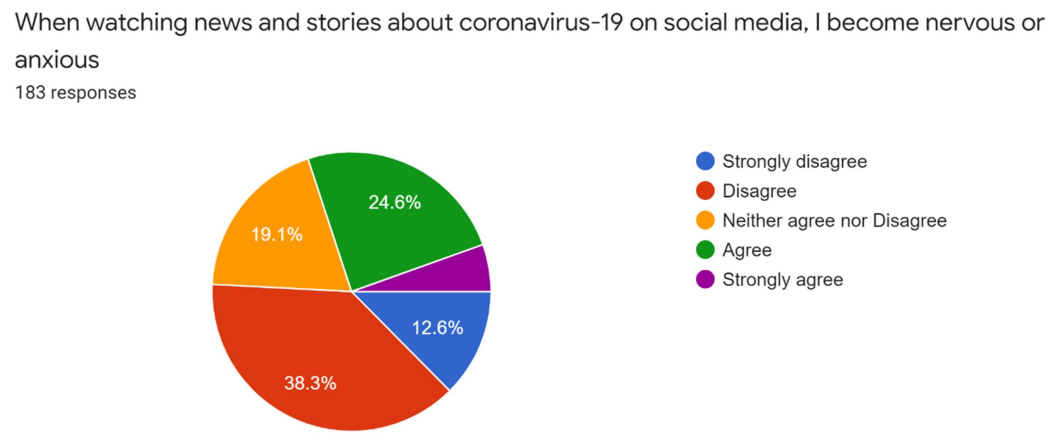

Strongly disagree

Disagree

Neither agree nor Disagree

- Agree

Strongly agree

VI) I cannot sleep because of I am worrying

i.e. 101 participants answered Disagree to this about getting coronavirus-19.:- - All question.

participants attended this question and mostly

I cannot sleep because l'm worrying about getting coronavirus-19.
183 responses

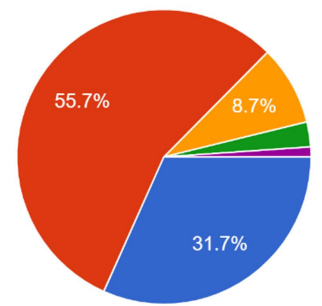

Strongly disagree

Disagree

Neither agree nor Disagree

Agree

Strongly agree

VII) My heart races or palpitates when I think

participants answered Disagree to this about getting coronavirus-19:- All participants question.

attended this question and mostly i.e. 97

My heart races or palpitates when I think about getting coronavirus-19.

183 responses

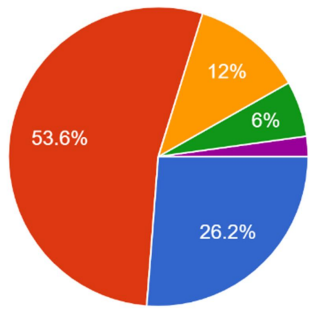

Strongly disagree

Disagree

Neither agree nor Disagree

Agree

Strongly agree

VIII) You have been vaccinated or not: - All participants attended this question. All Participants were vaccinated.
IX) If yes then which dose: - There were 4 participants were having first dose only rest 178 participants having both doses of vaccines. 


\section{DISCUSSION:-}

High infection rate and morality rate especially in the second wave of Covid -19 in India are the chief causes behind the fear about the Covid -19 infection.In India, 29.27 million cases have been reported so far during the second wave of pandemic, with a case fatality rate of $1.24 \%(363,079$ deaths) up to June $11,2021^{2}$. Though mass vaccination drive was started by the govt. of India from $16^{\text {th }}$ of January 2021. Still it was insufficient as compared with the population of India. Till $1^{\text {st }}$ of the December around 57.2\% eligible population was given $1^{\text {st }}$ dose and $32.5 \%$ having both doses of Vaccine. On the $24^{\text {th }}$ of November South Africa reported the new variant of Covid-19 i.e. Omicron was found. It has around 30 and more mutations as compared to the previous. Its infectious rate is higher but shows milder symptoms.

Due to sudden surge in Covid-19 cases in the month of December 2021 this study was undertaken to evaluate the fear among the undergraduate scholars of Parul Institute of Ayurveda Parul Unversity.

On the question I am most afraid of coronavirus-19:- Around 89 persons out of 183 strongly disagreedand Disagreed with this questions. This may be the impact of vaccination, but on the other hand 37 participants were agreed that they still afraid of Covid-19 virus infection this show the impact of fear is there. Another questions is thatit makes me uncomfortable to think about coronavirus-19:- 73 participants disagree with the statement. But 48 participants still uncomfortable when they think about Covid -19. This shows the fear of Covid -19. One more question is my hands become clammy when I think about coronavirus-19:- All participants attended this question and mostly i.e. 90 participants answered Disagree to this question. 20 participants either agree or strongly agree with this observation. This observation shows there is fear of Covid-19 definitely but very few having fear anxiety state, as in fear anxiety clammy hands is one of the symptom.

I am afraid of losing my life because of coronavirus-19 is one of the question in which 86 participants responded as either disagree or strongly disagree to this question. This shows impact of vaccination. As it's already proved. Vaccination markedly reduced adverse outcomes, with non-ICU hospitalizations, ICU hospitalizations, and deaths decreasing by $63.5 \% \quad(95 \% \mathrm{CrI}$ : $60.3 \%-66.7 \%$ ), 65.6\% (95\% CrI: $62.2 \%-$ $68.6 \%$ ), and $69.3 \%$ (95\% CrI: $65.5 \%-$ $73.1 \%$ ), respectively, across the same period $^{3}$

When watching news and stories about coronavirus-19 on social media, I 
become nervous or anxious this is the question. All participants attended this question and mostly i.e. 68 participants answered Disagree to this question still 55 participants either agree or strongly agree with this question i.e around $30 \%$ of participants. This shows the impact of social media on day to day life. In one REFERENCES:

[1] Ahorsu, D. K., Lin, C. Y., Imani, V., Saffari, M., Griffiths, M. D., \& Pakpour, A. H. (2020). The Fear of COVID-19 Scale: Development and Initial Validation. International Journal of Mental Health and Addiction, 1-9. Advance online publication.

https://doi.org/10.1007/s11469020-00270-8.

[2] Om Prakash Choudhary, Priyanka Indraj Singh and Alfonso J. Rodriguez-Morales. Second wave of COVID-19 in India: Dissection of the causes and lessons learnt. https://www.ncbi.nlm.nih.gov/pmc/ articles/PMC8214078/

[3] Seyed M. Moghadas, Thomas N. Vilches, Kevin Zhang, Chad R.
Study found a $70 \%$ increase in self-reported depressive symptoms among the group using social media ${ }^{4}$

\section{CONCLUSION:-}

There is definite impact of vaccination on the Covid-19 fear, but still in some cases fear plays a major role in aggravation of the disease.

Wells, Affan Shoukat, Burton $\mathrm{H}$. Singer, Lauren Ancel Meyers, Kathleen M. Neuzil, Joanne M. Langley, Meagan C. Fitzpatrick and Alison P. Galvani. The impact of vaccination on COVID-19 outbreaks in the United States. https://www.ncbi.nlm.nih.gov/pmc/ articles/PMC7709178/

[4] Fazida Karim, Azeezat A Oyewande, Lamis F Abdalla, Reem Chaudhry Ehsanullah, and Safeera Khan. Social Media Use and Its Connection to Mental Health: A Systematic Review. https://www.ncbi.nlm.nih.gov/pmc/ articles/PMC7364393 